\title{
Erratum to: Ancilla-induced amplification of quantum Fisher information
}

The Publishers

Società Italiana di Fisica and Springer-Verlag GmbH Germany, part of Springer Nature

Original article: Eur. Phys. J. Plus (2018) 133: 460, https://doi.org/10.1140/epjp/i2018-12260-2

Received: 13 November 2018

Published online: 30 November 2018

(c) Società Italiana di Fisica / Springer-Verlag GmbH Germany, part of Springer Nature, 2018

After publication the authors realized that the first sentence after eq. (13) had not been corrected. The sentence should read:

Here $\partial f_{\theta, \phi_{0}}\left(m_{i}\right) /\left.\partial \theta\right|_{\theta_{0}}$ quantifies the sensitivity of the observable $M$ to small fluctuations in $\theta$ around $\theta_{0}$.

The Publishers regret this mistake and apologize for any inconvenience caused. 